\title{
Employees' Occupational Health and Safety Awareness in Riyadh, Saudi Arabia
}

Baraa Alghalyini ( $\square$ balghalyini@alfaisal.edu )

Alfaisal University College of Medicine

\section{Tasnim Elgazzar}

Alfaisal University

\section{Abubakr Bajaber}

Alfaisal University

Muaz Wahed

Alfaisal University

Ayesha Ambia

Alfaisal University

Abdullah Binsaeedu

Alfaisal University

Museera Khan

Alfaisal University

Fatima Adem

Alfaisal University

Rand Azouz

Alfaisal University

Sana Elkhair

Alfaisal University

Fatma Mohamed

Alfaisal University

Raghad Alsaeed

Alfaisal University

Amel AlMakoshi

MoD

\section{Research}

Keywords: Occupational health and safety, occupational health awareness, OHAS, occupational health in Saudi Arabia, employees safety, employees first-aid training, employees health promotion, employees health in Saudi Arabia 
Posted Date: July 20th, 2020

DOI: https://doi.org/10.21203/rs.3.rs-42425/v1

License: (c) (i) This work is licensed under a Creative Commons Attribution 4.0 International License. Read Full License 


\section{Names and addresses of the authors:}

4

5

6

7

8

9

10

11

12 Arabia, fmohamed@alfaisal.edu RAlSaeed@alfaisal.edu Riyadh-11533, Saudi Arabia, balghalyini@alfaisal.edu

\section{Title: Employees' Occupational Health and Safety Awareness in}

\section{Riyadh, Saudi Arabia}

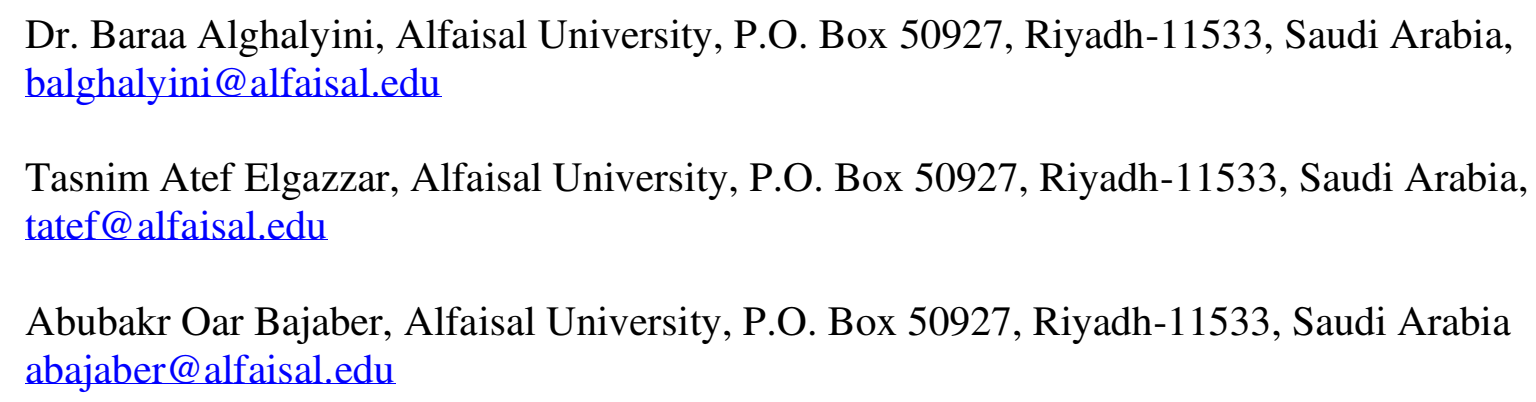

Fatma Mustafa Mohamed, Alfaisal University, P.O. Box 50927, Riyadh-11533, Saudi

Raghad Nabeel AlSaeed, Alfaisal University, P.O. Box 50927, Riyadh-11533, Saudi Arabia

Dr. Amel Almakhoshi, Ministry of Defense, Riyadh, Saudi Arabia,a.makoshi@gmail.com

Corresponding Author: Dr. Baraa Alghalyini, Alfaisal University, P.O. Box 50927, 


\section{Abstract:}

47 - Background:

$48 \quad$ Occupational hazards are extremely pervasive and preventive community-related

49 incidents occurring in occupations all over the world. In fact, the majority of developed

50 countries impose national policies to provide their employees with Occupational Health

51 and Safety (OHAS) guidelines and recommendations to avoid these hazards. Maintaining

52 and monitoring employee health through following (OHAS) laws in turn has a positive

53 impact on the economic status of the country.

54 Our study was conducted in Riyadh, KSA to fill a research gap on OHAS in the country,

55 and to collect evidence-based OHAS recommendations by focusing on three main

56 occupational health domains: stress, musculoskeletal and respiratory symptoms.

57 - Methods:

58 A validated structured questionnaire was administered on a cross-section of 319 randomly

59 selected employees aged 18 - 64 years in Riyadh for two weeks in Oct 2018. The survey

60 was conducted on site of 11 locations for different occupations. Information was sought

61 on their socio-demographic characteristics, first aid training and their awareness of major

62 occupational illnesses; stress, respiratory and musculoskeletal disorders. Factors such as

63 underlying diseases and confounding factors such as smoking were also taken into

64 consideration.

65

- Results:

66 A total of 319 employees were surveyed from eleven occupational backgrounds. Among all

67 the involved workplaces only 51.3\% of them offered First Aid training for the employees.

68 The prevalence of musculoskeletal disorders was $24.1 \%$ for weakness followed by $16 \%$ for pain. Around $70 \%$ of respondents denied suffering from stress at work, neither experiencing 
stress- related symptoms such as headache, sleeplessness or anxiety attacks as a result of their work.

\section{Conclusion:}

73 This student-led community engaging study aimed to evaluate employees' awareness of

74 illnesses related to their occupations and their practices to prevent them. Under the supervision of College of Medicine faculty members at Alfaisal University,1st and 3rd year medical students visited different worksites including schools, dental clinics, car shops, airport terminals, and others to present a brief presentation to promote occupational health and safety proceeded by the distribution of a brief survey. Although musculoskeletal, respiratory and mental illnesses are commonly observed occupation- related complaints, yet this wasn't evident in our study. This could be explained by employees' lack of awareness or fear of reporting their health concerns. This observed gap in our study will help in recommending national guidelines to promote occupational health and safety across different occupations.

\section{Background:}

The International Labor Organization defines Occupational health and safety (OHAS) as "the promotion and maintenance of the highest degree of physical, mental and social well-being of workers in all occupations" 1 . Recently, OHAS has become increasingly important and challenging due to several prominent influences, including technology-generating hazards, increased level of workplace violence, and other financial and environmental factors 2.

Occupational hazards is one of the causes of morbidity and mortality worldwide, ranking 11th for men and 13th for women in terms of disability-adjusted life years (DALYs) 3. An estimated 2.3 million occupationally related deaths are reported each year globally (4).

93 The primary purpose of this study is to obtain an insight into the awareness and prevalence of the top 3 reported occupational hazards in different work environments. The top 2 leading 


\section{Summary of existing Literature:} the primary factors of occupational stress.

\section{OHAS areas of focus:}

health hazards are stress and musculoskeletal disorder in recent years (5). With changing environmental exposures and increasing rate nationally, asthma was included as occupational asthma as the most prevalent lung disease. Occupational health and safety concerns and measurement has increased internationally while few have been initiated at a national level. Our literature review showed very few studies focused on occupational health and safety. Of the studies conducted each found in general a gap in awareness and preventive measures in place to reduce occupational hazards. Our study wanted to assess the awareness and presence of OHAS measures in different work settings and the rate of the occupational hazards reported by profession. To the best of our knowledge there is no published article on occupational asthma for the Saudi population. Whereas, occupational stress was studied in 2003 to assess work-related characteristics of paramedical stress in PHC employees (6). The study took place in Abha, evaluating the employee perspective of occupational stress factors. The study concluded that workload, limited decision autonomy, and language barrier were

Regarding musculoskeletal disorders, our literature review found three published articles in different regions of the country; Jizan, Makkah, and Dammam. The study population assessed were hospital staff. The level of postural awareness was evaluated using selfadministered questionnaires. Each has concluded that awareness and preventive measures were a significant factor in occupational musculoskeletal disorders 7,9.

The Occupational Health and Safety (OHAS) Program mandates specific rules of conduct to ensure optimal workplace conditions entitled to all workers without compromising their protection factors in their work environment. The following defines the protocol for securing 
occupational health and safety measures for respiratory, musculoskeletal, and stress in workers of the appropriate environment where they are to be implemented.

\section{Respiratory:}

123 The recommended OHAS implementations for Respiratory Protection Program (RPP)

124 encompass nine components which are "evaluation of respiratory hazards; selection of respiratory protective equipment (RPE); medical evaluation; fit testing; training; use of RPE; inspection, cleaning, and maintenance of RPE; program evaluation; and recordkeeping.” (10).

127 Now the rapid economic growth in developed and developing countries has produced a

128 paradigm shift in occupational health; due to the construction of the vast industrial sector,

129 which introduced a deluge of work-related silica and asbestos $(11,13)$. Low-dose allergens and chemical irritants exposure necessitated the importance of surveillance programs, standard occupational exposure limits and OHAS protocol backed up by evidence-based research (1113). Today, fortunately, the rise of climate change mitigation policies has led to a decrease in dependence on fossilized fuels from coal mining, declining coal mine dust exposure and consequently the frequency of pneumoconiosis. The global population who get unregulated and unrecognized exposure in the workplace contribute to a heavy burden of disease (11-13). Among the general population, the most afflicted vulnerable population include the aged, low socio-economic class, and migrants. New emerging respiratory hazards from recent technological leaps include nanomaterials, called manufactured carbon nanotubes. Their functionality in health outcomes is not fully understood, but has physical and chemical properties similar to asbestos, causing pulmonary inflammation and fibrosis. They are found in laser printers and photocopiers and are also classified as potentially carcinogenic. $(12,14)$.

142 Ever since the incidence of immunologic, interstitial and mutagenic lung diseases had been

143 highly unacceptable in the past decades, the mainstay OHAS focus now is on occupational

144 asthma among other pulmonary diseases due to growing statistical evidence of its adverse 
work disadvantages. Generic methods to control and prevent asthma and its exacerbating events have been taken, but there is still much to be done in terms of informal hazard

147 detection and continued evaluation of asthma safety in workplaces $(11,12,15,16)$. It is a legal

148 requirement to carry out health surveillance in various circumstances, as it is recommended

149 by the WHO to put in place "systematic, regular and appropriate procedures to detect early signs of work-related ill-health among employees exposed to certain health risks; and acting on the results." Despite that, surveillance is quite often overlooked in workplaces and requires standardization to reinforce employee education and training $(13,17)$.

\section{Musculoskeletal:}

154 Work-related musculoskeletal disorders (WMSD) represent a wide array of pathological 155 conditions that, after repeated physical stressors to the soft tissues, affect the health and work performance of the employees, even leading to temporary or permanent disabilities (18). It may also include fractures, cuts, strains, loss of limbs, or repetitive motion disorders (19) Irrespective of the field of work or gender, the most common musculoskeletal symptoms (MSS) include lower back, shoulders, and neck. In gender terms, females had hand or wrist pain, hip, and thigh pain, apart from the general MSS whereas the males had more symptoms of pain in elbows and knees (20).

The incidence of WMSD in dentists and orthodontists is especially high due to prolonged, forced, awkward, and mostly incorrect positions; straining the muscles, joints, and tendons, increased muscle tension, and spinal problems. Also, lower back pain, neck pain, and visual strains are not uncommon symptoms in such professionals with most reporting pain in more than one part of the body $(21,22)$.

167 The key to effective implementation is based on proper education and ergonomic training,

168 effective communication, participation and support, and effective and efficient

169 implementation (18). Moreover, there should be a basic facility for biofeedback training and 
job stress management training (23). In evaluating WMSD, however, it should be noted to

171 factor cultural bias for pain assessment due to the nocebo effect, by negatively assuming

172 adverse health situations, and manifesting more harmful effects (24).

173 Stress:

174 Occupational stress and adverse mental health effects can cause detrimental effects on

175 workers and the organization as a whole. It may lead to career uncertainty, high turnover,

176 poor performance, low morale, health problems, and absenteeism (25). Burnout is a

177 psychological condition stemming from chronic stress, leading to a lack of commitment,

178 emotional and physical exhaustion, and job dissatisfaction. It is a risk factor for various

179 diseases and comorbidities, such as coronary artery disease, hypercholesterolemia, sleep

180 disorders, obesity, sedentarism, depression, and increased alcohol consumption. It is

181 characterized by emotional depletion, lack of energy, cynicism, depersonalization, inefficacy,

182 poor job performance, and poor coping skills. The job demand-resources (JDR) model states

183 that increased work stressors and burnout lead to adverse outcomes; whereas work resources

184 and support lead to positive outcomes and greater motivation (26). Psychological stress has

185 been one of the biggest OHAS concerns after WMSD. Work overload, interpersonal conflict,

186 and organizational constraints have been proven universal.

187 Research shows that mindfulness plays a beneficial role in lowering the risk of mental

188 disorders, leading to higher interpersonal and intrapersonal well-being $(27,28)$. There is an

189 increased need for laying down job stress management strategies in workplaces, and they can

190 be classified as primary, secondary, and tertiary based on their implementations. Primary

191 interventions are organizational preventative strategies that optimize work and health

192 outcomes. They include job redesigns for reducing stressors by providing flexible hours.

193 Secondary interventions aim to provide assistive tactics for stress-coping, like stress 
management or employee wellness programs, social and recreational facilities. On the other hand, tertiary interventions, like counseling and rehabilitative programs, are curative. $(25,29,30)$.

OHAS Laws of KSA:

197 Local requirements of OHAS focuses primarily on the general laws and regulations set out

198 for the employers that mandate the protection of OHAS and employees' health by the

199 employers. They have not provided an in-depth, comprehensive framework of guidelines to

200 follow for general and occupation-specific OHAS issues. The local KSA laws are grouped and summarized into the following points:

1. The employer shall not terminate the worker's contract without remuneration, notice ,or compensation, except in cases where there is a major violation of the contract's statement. (Article 80)

2. The employer is mandated to provide break times during work which should not exceed the maximum number of hours, hygienic environment, and clear instructions

3. The employer must provide fire and accident prevention OHAS services, and cover employee expenses due to occupational accidents. They are required to provide partial financial aid for temporary cases for a designated period. If total disability or death occurs due to occupational causes, then employees are entitled to wage compensation for three years. (Article 125, 135, 137, and 138)

4. Article 139 states that articles 133,137 , and 138 are inapplicable in cases of deliberate self-injury, injury due to misconduct or refusal of treatment.

5. The workplace must have first aid cabinets, access to physician for occupational health issues, and preventive and management procedures put forward by the employer in accordance with the Ministry of Labor laws. (Article 142, 143) 
219 Methods:

220

221

222

223

224

225

226

227

228

229

230

231

232

233

234

235

236

237

- Design and Setting of Study: A validated structured questionnaire was administered on a cross-section of 319 randomly selected employees aged 18 - 64 years in Riyadh for two weeks in Oct 2018. The survey was conducted on site of 11 locations for different occupations. Information was sought on their socio-demographic characteristics, first aid training and their awareness of major occupational hazards; stress, respiratory and musculoskeletal disorders. Factors such as underlying diseases and confounding factors such as smoking were also taken into consideration This study was descriptive and crosssectional in design. A sample size of 319 was obtained based on the following assumptions; $95 \%$ confidence level, and a 5\% margin of error. The random sampling technique was used in selecting respondents from the study population during random visits to 11 locations for different occupations. Occupations included were: teachers, dentists, lab technicians, medical technologists, forensics, salon workers, cleaning workers, policemen, airport workers, construction workers, and carshop repairmen. Verbal consent was obtained from prospective respondents prior to administration of the surveys. Approval for the study was obtained from the institutional review board at Alfaisal University.

- Characteristics of Participants: The study was carried out among employees aged 18 64 years working in Riyadh in Oct 2018

- Description:

In this study, we focused on three aspects of the occupational hazards, the psychological, respiratory, and musculoskeletal, due to their high prevalence in Saudi Arabia and the minimal research on them that is specific for certain exposures and demographics in most of the studies. According to a local study, some respiratory problems (wheezing and 
shortness of breath) are related to the levels of occupational exposure to chemicals and dust while other symptoms (cough and phlegm) are usually caused by smoking which make it a major confounder for respiratory symptoms $(31,32)$. Stress seemed to be of concerning levels, especially among nurses in the health-care sector $(33,34)$. Moreover, a study was conducted on computer users of three public institutions in Saudi Arabia using an international standardized form entitled "Ergonomics Rating of Computer Applications" to assess the ergonomic status, found an increased musculoskeletal symptoms in relation to decreased ergonomic score of computer workstation (35-36). A validated structured self-administered questionnaire containing closed-ended questions was used. Information was sought on respondents' socio-demographic characteristics, their awareness of major occupational hazards and their first aid training. Major occupational diseases included were: respiratory disorders, musculoskeletal disorders, and stress. In order to avoid a discussion regarding the questions among the respondents, the questionnaire was distributed to each of them and when answered, it was collected personally by one of the authors immediately.

The data was cleaned and analyzed using EXCEL version 2005. Quantitative variables were analyzed using mean and standard deviation. Categorical variables were summarized using percentages and frequencies. Bivariate analysis was used for testing the significance of associations between categorical variables. The level of significance

\section{Results:}

264 Our study has shown that almost $60 \%$ of respondents completed undergraduate education 265 (See Fig-1). Moreover 37\% confirmed a smoking history either currently or in the past, with 266 the majority working as a "carshop repairmen", "policemen" and "construction workers" 267 (See Fig-2). The prevalence of musculoskeletal disorders was $24.1 \%$ for weakness followed 
by $16 \%$ for pain (See Fig-4 ). The self-reported stress among the population was $20.1 \%$, with cleaning workers demonstrated the highest percent of employees' stress (See Fig-6).

270 Furthermore, there is almost equal distribution in the sample, between those who attended an occupational safety orientation seminar and those who did not. From among the attendees,

272 "medical technologists" and "Forensics " were the majority. Also, almost half of the respondents confirmed receiving first aid training, with the majority from the "dentist" group

274 (See Fig-3).

275 In parallel to the previous finding, the availability of first aid kits at the workplace was 276 acknowledged mostly by "dentists".

277 Additionally, the majority of respondents reported they did not suffer from respiratory 278 symptoms like asthma( see Fig 5), or chronic problems including diabetes, hypertension, 279 chronic musculoskeletal complaints, and mental illnesses like anxiety etc. This was found among all occupations included in this study.

Unexpectedly, almost $70 \%$ of respondents denied suffering from stress at work, neither experiencing stress- related symptoms such as headache, sleeplessness or anxiety attacks as a result of their work with the highest percent being among cleaning workers (See Fig-6 ).

\section{Discussion:}

285 Our paper clearly elucidated a significant gap in the attention given to the health of employees in the city of Riyadh, Saudi Arabia, and further steps need to be undertaken in order to move forward. Many workplaces offer occupational safety orientation seminars, yet the quality of such seminars and if appropriate measures are being implemented from the employees' end is questionable. Also, the fact that dentist and lab technicians' groups confirmed receiving first aid training was quite expected due to the contract renewal requirement of BLS "Basic Life Support" course for all medical and dental facilities in Saudi Arabia. It is needed to attain accreditation through International and National accrediting 

awareness of the lack of occupational health \& safety measures, like first aid training, across other non-health sectors to the Ministry of Labor for implementation and enforcement of occupational safety laws. Furthermore, such observation can also instigate production of improved occupational health and safety legislation.

The survey inquired specifically about occupation-induced respiratory symptoms such as dermatology-related complaints. These symptoms are often observed in the literature as a common occupational-related presentations, but this wasn't the case in this study (40-43). This odd link may be due to the respondents' concern of victimization, as disclosing any healthrelated complaints might make them susceptible to criticism from employers, along with its sequelae of penalties, salary reduction, non-renewal, or even immediate termination of their contracts.

\section{Limitations:}

309 Our study was conducted as part of an undergraduate medical students' project for their

310 Primary Care and Public Health course. The course took place over the fall semester only,

311 imposing a major time limitation. In addition, students had to balance between attending

312 lectures at university and allocating proper time slots to visit different workplaces and coordinate it with their schedules. Another limitation was to gain the workplace owners' trust and gain approval to allow students to visit the sites and survey the employees. This alone required several visits and attempts to convince that no data will be shared with any authority or third party; as well as reassurance of proper handling of the data with confidentiality. 
317 Despite the small sample size and the fact representation from each occupation varied which

318 limits compatibility between them, yet our study is considered unique in a sense that it also

319 engaged the first and third year medical students with their local community. It has provided

320 vital practical experience from the community through live lessons of cases, the likes of

321 which they will manage in their future professional practice. Moreover, Occupational Health

322 is a topic rarely discussed at the undergraduate level. Hence, this project has created an opportunity to introduce this field to some, while building on existing understanding for

324 others.

\section{Conclusion:}

326 Our study has shed light on an essential yet overlooked public health concern for many

327 employees working in Riyadh. In order to achieve the Kingdom's latest 2030 vision goals,

328 with Riyadh being the epicenter of development, this issue should not be taken lightly, as

329 efficient employees are the nation's golden resource.

330 Although the focus being assessment of employees' awareness of occupation-related health presentations, the identified gap was primarily in areas of commonly observed occupationrelated presentations, which were not reflected by respondents of our study. This could partly be due to the restricted scale of study. A work environment which doesn't support employees' feedback, as well as cultural limitations, or language barriers are other potential explanations. Hence calling the need to conduct further study in this particular field.

\section{Keywords:}

338 Occupational health and safety, occupational health awareness, OHAS, occupational health in Saudi Arabia, employees safety, employees first-aid training, employees health promotion, employees health in Saudi Arabia. 
342 List of Abbreviations:

343 OHAS: Occupational Health and Safety

344 CBAHI: Saudi Central Board for Accreditation of Healthcare Institutions

345 WMSD: Work-related Musculoskeletal Disorders

346 JCI: Joint Commission International

347 KSA: Kingdom of Saudi Arabia

348 ILO: International Labour Organisation

\section{Declarations:}

1. Ethics approval and consent to participate: attached IRB approval.

2. Consent for publication: Not applicable

3. Availability of data and materials: The datasets used and/or analyzed during the current study are available from the corresponding author on reasonable request.

4. Competing interests: The authors declare that they have no competing interests

5. Funding: Hereby declare that the funding is contributed personally by the main author.

6. Authors' contributions: BG conceptualized, supervised all the team, discussed, concluded the whole project; analyzed, interpreted the data; overseeing all the participating individuals; TAE prepared the introduction and literature review, MMW, FMM, RNA ASB, ARA, RJA, MIK, AOB, FA, SAE participated in various interviews with the participants and conducted surveys; AA Offered her expertise in biostatistics to supervise and guide the team around data management and analysis.

7. Acknowledgements: Mr. Ahmed Sayeed Khan, Alfaisal University, P.O. Box 50927, Riyadh11533, Saudi Arabia for his administrative assistance. 


\section{References:}

1- Robson L., Clarke J., Cullen K., Bielecky A., Severin C., \& Bigelow P. et al. The effectiveness of occupational health and safety management system interventions: A systematic review. Safety Science. 2007;45(3):329-353.

2- Goetsch D. Occupational Safety and Health for Technologists, Engineers, And Managers, 7th Edition | Occupational Safety And Health Administration | Occupational Hygiene. [online] Scribd. 2011.

3- Rushton L. The Global Burden of Occupational Disease. Current Environmental Health Reports. 2017;4(3):340-348.

4- Takala J., Hämäläinen, Saarela K., Yun L., Manickam K., \& Jin T. et al. Global Estimates of the Burden of Injury and Illness at Work in 2012. Journal Of Occupational And Environmental Hygiene. 2014;11(5):326-337.

5- Health and Safety Executive. Statistics - Work-related ill health and occupational disease. [online]. 2019.

6- Abdelmoneim I. Occupational stress among paramedical staff working in primary health care centers in Abha, Saudi Arabia. J Egypt Public Health Assoc. 2003;78(5-6):387-96.

7- Kanaparthy A, Kanaparthy R, Boreak N. Postural awareness among dental students in Jizan, Saudi Arabia. J Int Soc Prev Community Dent. 2015;5(Suppl 2):S107-11.

8- Bin Homaid M, Abdelmoety D, Alshareef W, Alghamdi A, Alhozali F, Alfahmi N, Hafiz W, Alzahrani A, Elmorsy S. Prevalence and risk factors of low back pain among operation room staff at a Tertiary Care Center, Makkah, Saudi Arabia: a cross-sectional study. Ann Occup Environ Med. 2016;28(1). 
9- AlQahtani SM, Alzahrani MM, Harvey EJ. Prevalence of musculoskeletal disorders among orthopedic trauma surgeons: an OTA survey. Can J Surg. 2016;59(1):42-7.

10- Honarbakhsh M., Jahangiri M., Ghaem H., Farhadi P. Respiratory Protection Program Compliance in Iranian Hospitals: Application of Fuzzy Analytical Hierarchy Process. [online] SAGE Journals. 2017.

11- Cullinan P, Muñoz X, Suojalehto H, Agius R, Jindal S, Sigsgaard T, Blomberg

A, Charpin D, Annesi-Maesano I, Gulati M, Kim Y, Frank AL, Akgün

401

M, Fishwick D, de la Hoz RE, Moitra S. Occupational lung diseases: from old and novel exposures to effective preventive strategies. - Lancet Respir Med. 2019;5(5): 445-455.

404

405 Henneberger, P. et al. Current and new challenges in occupational lung diseases. European Respiratory Review. 2017;26(146):170080.

13- Boel NM, Klokker M. Upper respiratory infections and barotrauma among commercial pilots. Aerosp Med Hum Perform. 2017;88(1):17-22.

14- Suganuma N., Natori Y., Kurosawa H., Nakano M., Kasai T., Morimoto Y. Japan Society for Occupational Health Occupational Lung Disease Study Group. Update of occupational lung disease. Journal of occupational health. 2019;61(1):10-18.

15- Lin S., Lawrence W.R., Lin Z. et al. Int Arch Occup Environ Health. 2017;90: 725.

16- Quirce S., Vandenplas O., Campo P., Cruz M., de Blay F., \& Koschel D. et al. Occupational hypersensitivity pneumonitis: an EAACI position paper. Allergy. 2016;71(6):765-779. 

disease, Occupational Medicine. 2013;63(5):322-334. prevent musculoskeletal disorders and how to systematically address them. Applied Ergonomics. 2018;73:122-140.

19- Occupational Health: MedlinePlus. 2019.

20- Widanarko B., Legg S., Stevenson M., Devereux J., Eng A., \& Mannetje A. et al.

Prevalence of musculoskeletal symptoms in relation to gender, age, and occupational/industrial group. International Journal Of Industrial Ergonomics. 2011;41(5):561-572.

21- Gopinadh A., Naga K., Devi N., Chiramana S., Manne P., Sampath A., \& Babu M. S. Ergonomics and Musculoskeletal Disorder : As an Occupational Hazard in Dentistry. 2013;14:299-303.

22- Sakzewski L., \& Naser-ud-Din S. Work-related musculoskeletal disorders in dentists and orthodontists: A review of the literature. Work. 2014;48(1):37-45.

23- Kennedy C.A., Amick III B.C., Dennerlein J.T. et al. J Occup Rehabil. 2010;20: 127.

24- Coggon D., Ntani G., Palmer K., Felli V., Harari R., \& Barrero L. et al. Disabling musculoskeletal pain in working populations: Is it the job, the person, or the culture?. Pain. 2013;154(6):856-863.

25- Babatunde A. Occupational Stress : A Review on Conceptualisations, Causes and Cure. 2013;65(3):73-80.

26-Salvagioni D., Melanda F., Mesas A., González A., Gabani F., \& Andrade S. Physical, psychological and occupational consequences of job burnout: A systematic review of prospective studies. PLOS ONE. 2017;12(10):e0185781. 
27-Guillaumie L., Boiral O., \& Champagne J. A mixed-methods systematic review of the effects of mindfulness on nurses. Journal Of Advanced Nursing. 2016;73(5):1017-1034.

28- Mazzola J., Schonfeld I., \& Spector P. What qualitative research has taught us about occupational stress. Stress And Health. 2011;27(2):93-110.

29- Awang Idris M., Dollard M. and Winefield A. "Lay theory explanations of occupational stress: the Malaysian context", Cross Cultural Management: An International Journal. 2010;17(2):135-153.

30- Richardson K. M. Managing employee stress and wellness in the new millennium. Journal of Occupational Health Psychology. 2017;22(3):423-428.

31- Seifeddin G. Ballal, Hafiz O. Ahmed, Basil A. Ali, Adnan A. Albar \& Abdullah Y. Alhasan. Pulmonary Effects of Occupational Exposure to Portland Cement: A Study from Eastern Saudi Arabia, International Journal of Occupational and Environmental Health. 2004;10:3:272-277.

32- Abbas M., Zakaria A., \& Balkhyour M. Investigation of safety facilities and safe practices in chemical laboratories of a Saudi university. Journal Of Environment And Safety. 2015;7(2):141-147.

33- Aburuz M. The impact of stress on job satisfaction for nurses in King Fahad Specialist. Journal of American Science. 2013;9(3):371-377.

34- Mersal F. A. Effects of Job Stress on Health of Saudi Nurses Working in Ministry of Health Hospitals in Qassim Region in KSA. Life Science Journal. 2013;10(1).

35- ABBAS M., ZAID L., FIALA L., \& ALHAMDAN N. PREVALENCE AND RISK FACTORS OF LOW BACK PAIN AMONG NURSES IN FOUR TERTIARY CARE HOSPITALS AT KING FAHAD MEDICAL CITY, RIYADH, KSA. The Medical Journal Of Cairo University. 2010;78(2). 
36- Darwish M., \& Al-Zuhair S. Musculoskeletal Pain Disorders among Secondary School Saudi Female Teachers. Pain Research And Treatment. 2013:1-7.

37- Muaidi Q., \& Shanb A. Effects of work demands on physical therapists in the KSA. Journal Of Taibah University Medical Sciences. 2016;11(1):56-62.

38- Jomoah I. Work-Related Health Disorders among Saudi Computer Users. The Scientific World Journal. 2014:1-27.

39- Labor Rules \& Regulations. Ministry of Labor and Social Development. 2019.

40- Nuraydın A., Bilek Ö., Kenziman A. K., Korkusuz M. A., Atagün A. İ., Çakar N. Ö., Özer N., Deniz S., Başaralı M. K., Özlü A., Sandal A., Van der Laan G., \& Y1ld1z A. N. The Mersin Greenhouse Workers Study. Surveillance of Workrelated Skin, Respiratory, and Musculoskeletal Diseases. Annals of global health. 2018;84(3):504-511.

41- Fernandes M. A., Soares L., \& Silva J. Work-related mental disorders among nursing professionals: a Brazilian integrative review. Revista brasileira de medicina do trabalho : publicacao oficial da Associacao Nacional de Medicina do Trabalho-ANAMT. 2018;16(2):218-224.

42- Hossain M. D., Aftab A., Al Imam M. H., Mahmud I., Chowdhury I. A., Kabir R. I., \& Sarker M. Prevalence of work related musculoskeletal disorders (WMSDs) and ergonomic risk assessment among readymade garment workers of Bangladesh: A cross sectional study. PloS one. 2018;13(7):e0200122.

43- Occupational Safety And Health Administration | UNITED STATES Department Of Labor | Dermal Exposure. 2018. 
490 Figures, Tables and additional Files:

491

492 1. Fig-1: Graph showing Age Group and Educational level

Fig 1-Age group and Educational Level $(\mathrm{N}=319)$

$35.00 \%$

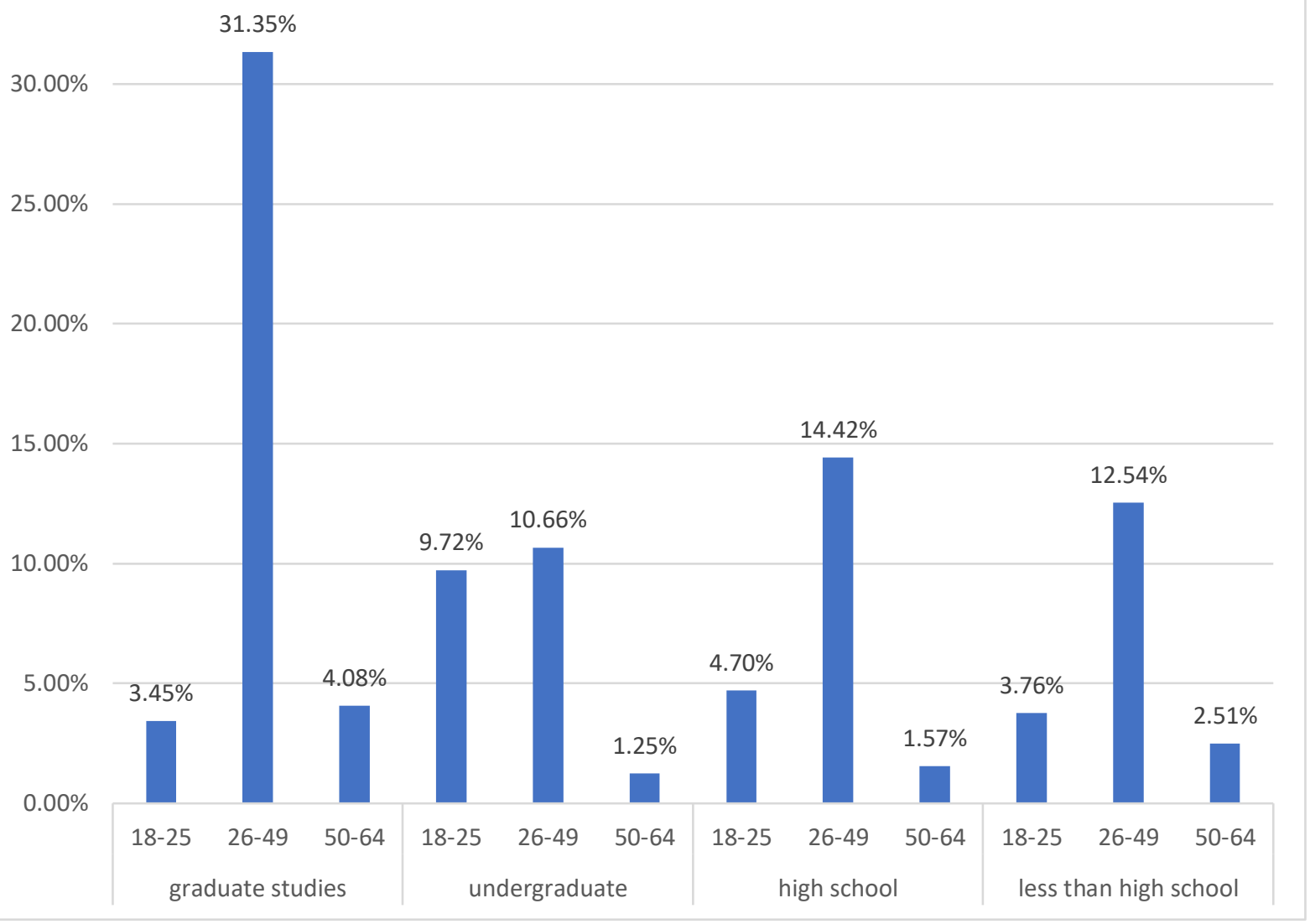

493

Education level distribution per age group; percentage of grand total for each category 


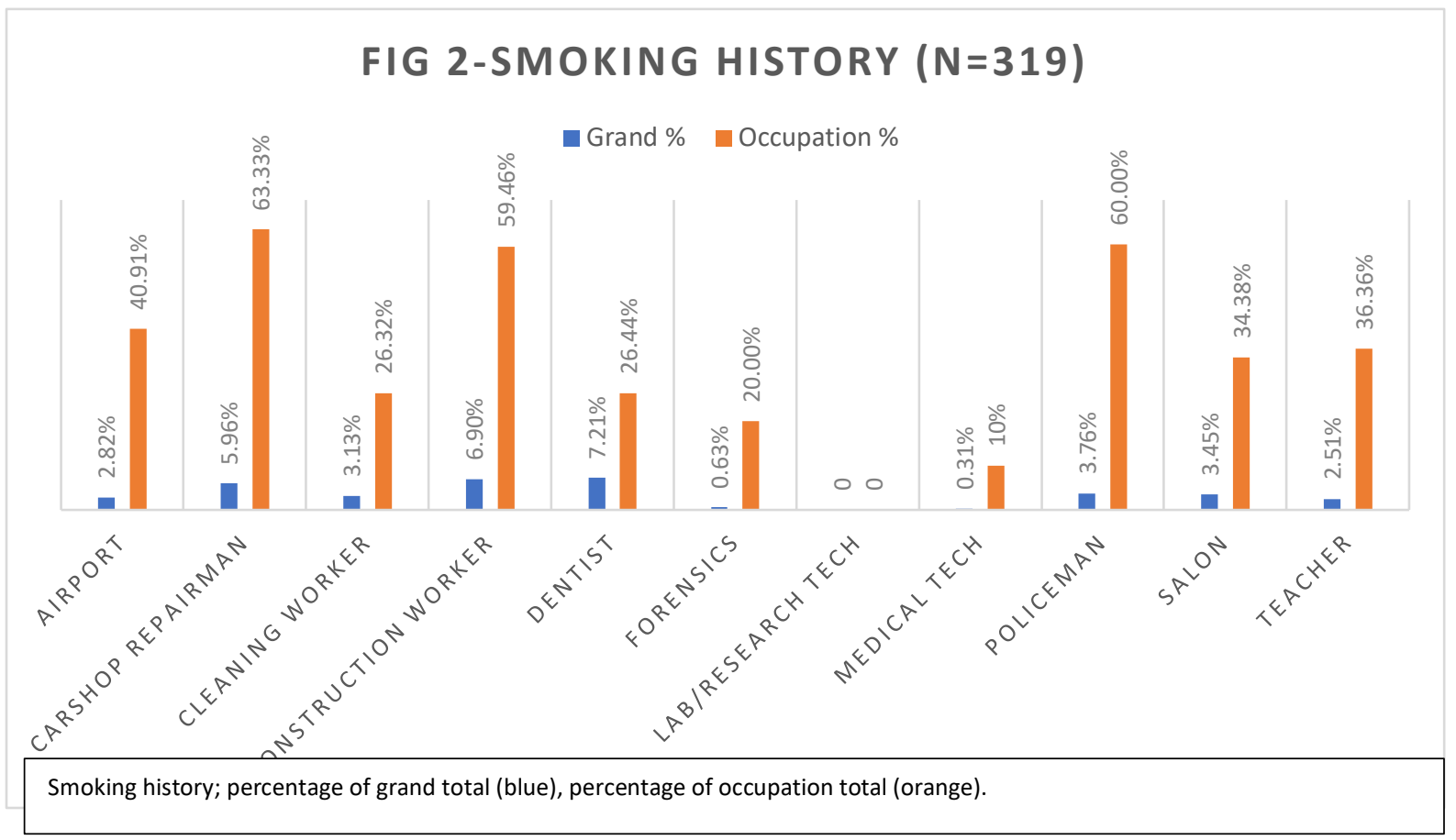

497

3. Fig-3: Safety Training

\section{FIG-3 SAFETY TRAINING}

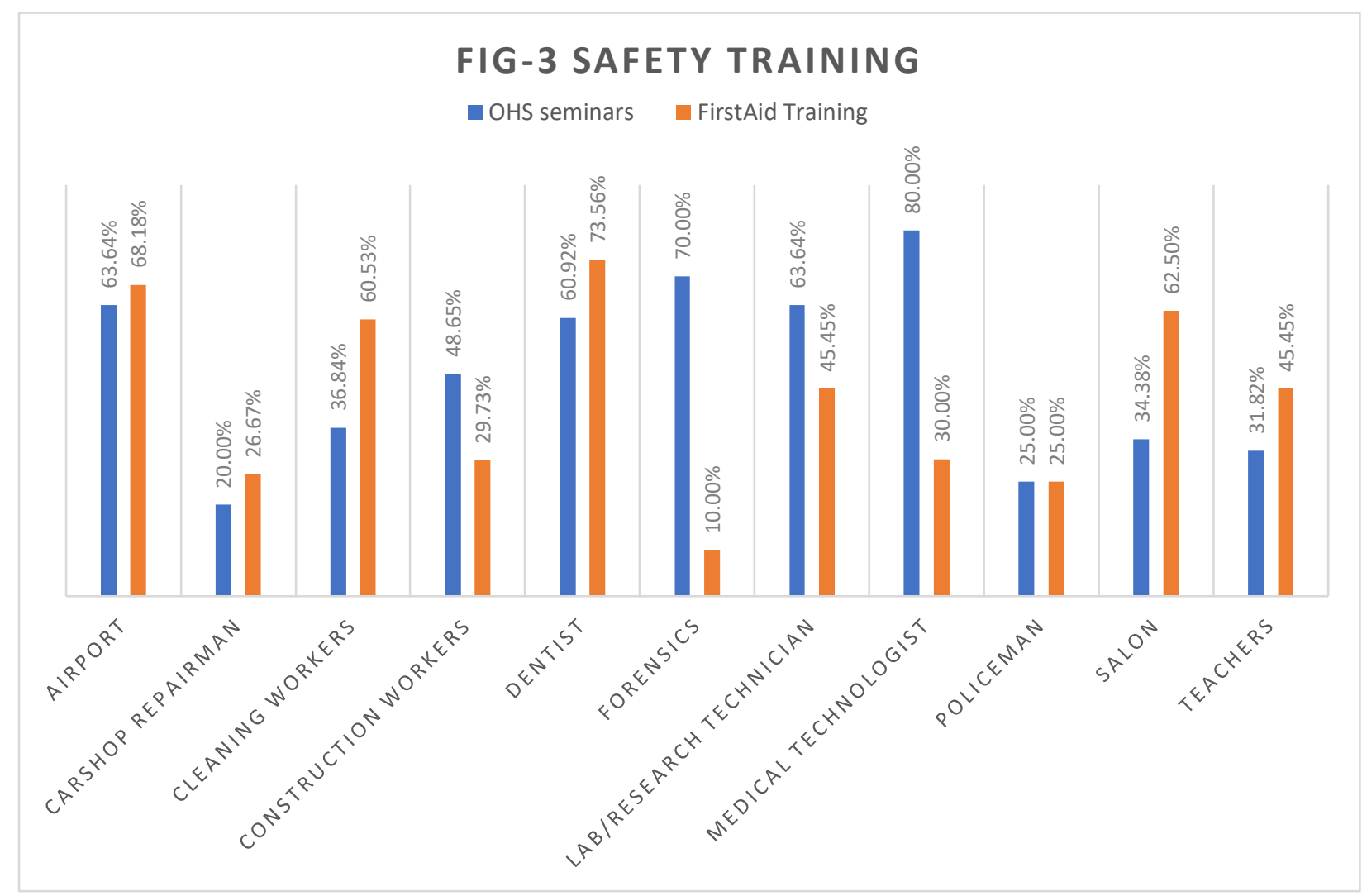

499 


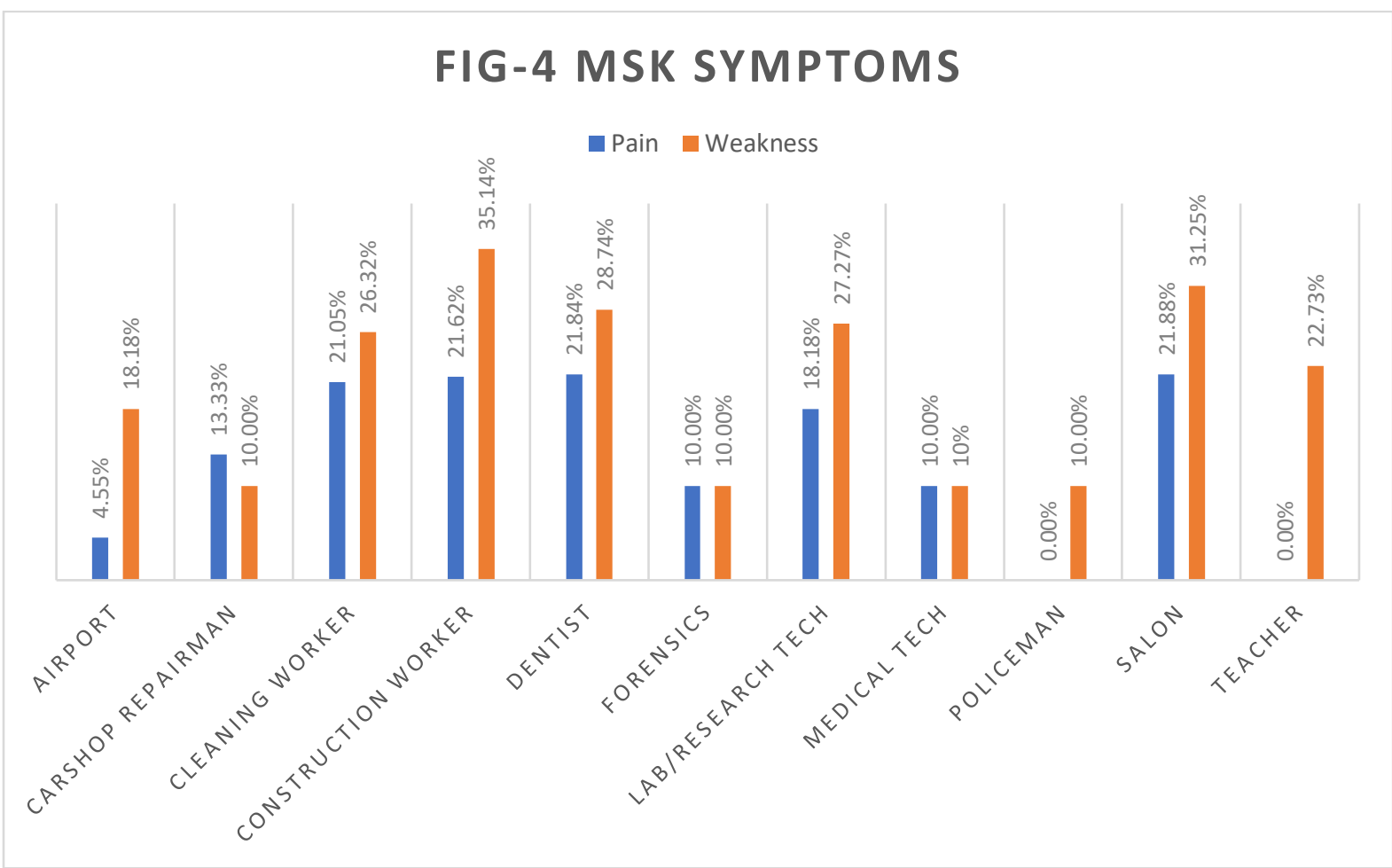

502

503

MSK occupation- related Symptoms; percentage of occupation total for Pain (blue) and Weakness (orange).

504

5. Respiratory Symptoms

\section{FIG-5 RESPIRATORY SYMTOMS}

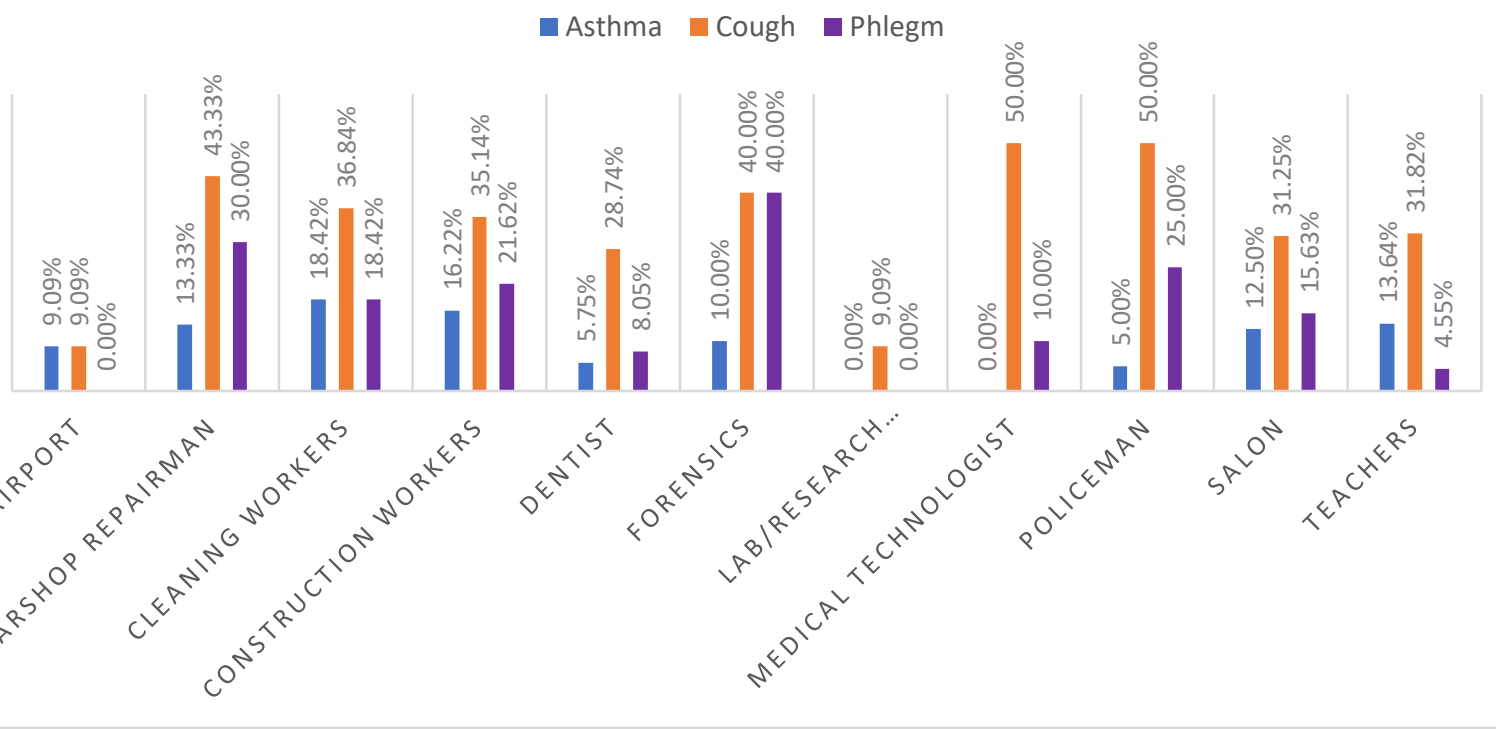




\section{FIG-6 PSYCHIATRIC SYMPTOMS}

6.

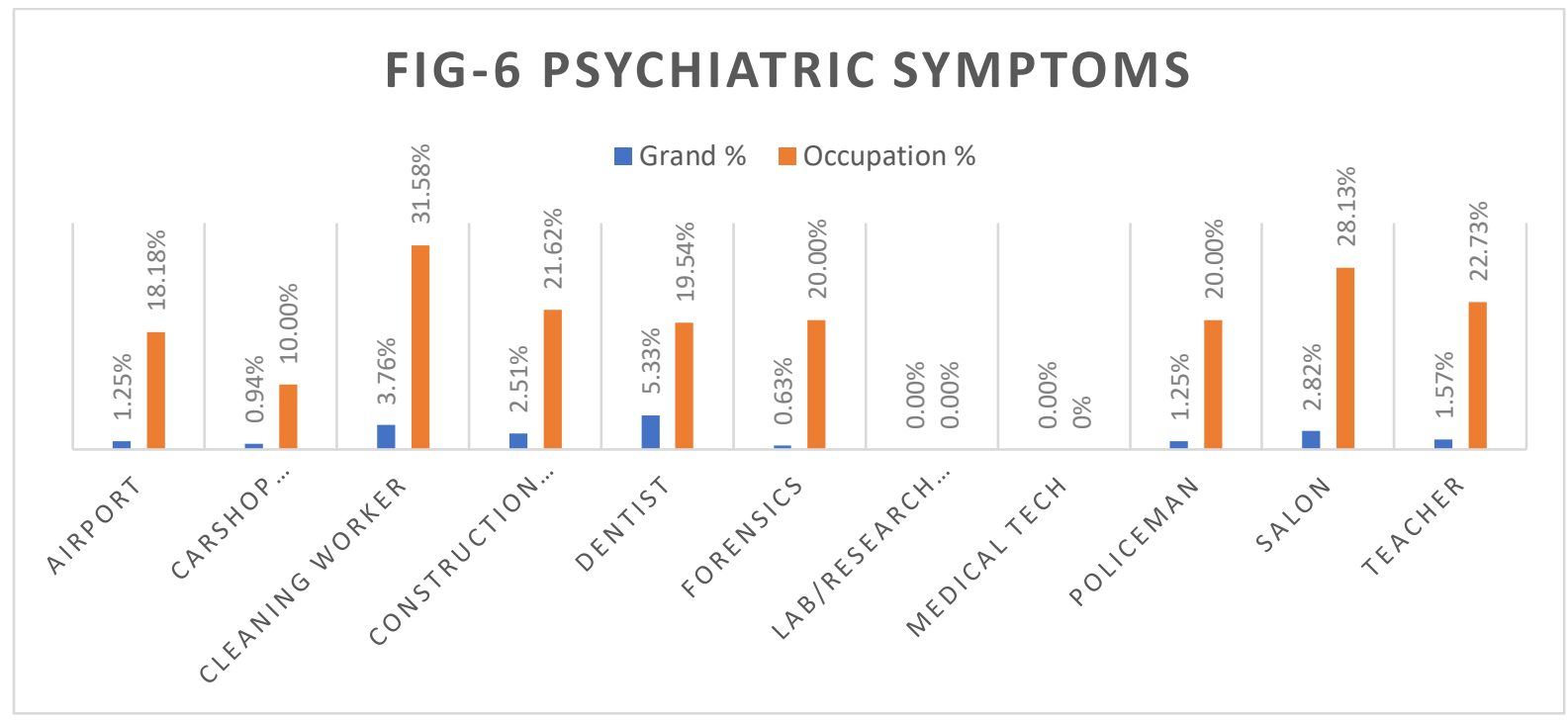

510

Stress and Anxiety; percentage of grand total (blue), percentage of occupation total (orange).

511 Table 1. Distribution of Occupation based on gender:

\begin{tabular}{lrr} 
& \multicolumn{3}{c}{$\%$ of } \\
Occupations & Count of Occupation & Occupation \\
\hline Females & $\mathbf{1 7 2}$ & $\mathbf{5 3 . 9 2 \%}$ \\
\hline Dentist & 61 & $35.47 \%$ \\
Salon & 32 & $18.60 \%$ \\
Cleaning workers & 28 & $16.28 \%$ \\
Teachers & 22 & $12.79 \%$ \\
lab/research & & \\
technician & 11 & $6.40 \%$ \\
Airport & 10 & $5.81 \%$ \\
Medical Technologist & 8 & $4.65 \%$ \\
Males & 147 & $46.08 \%$ \\
\hline Construction worker & 37 & $25.17 \%$ \\
Carshop Repairman & 30 & $20.41 \%$ \\
Dentist & 26 & $17.69 \%$ \\
policeman & 20 & $13.61 \%$ \\
Airport & 12 & $8.16 \%$ \\
Cleaning workers & 10 & $6.80 \%$ \\
Forensics & 10 & $6.80 \%$ \\
$\quad$ Medical Technologist & 2 & $1.36 \%$ \\
\hline Grand Total & 319 & $\mathbf{1 0 0 . 0 0 \%}$
\end{tabular}

512 
Figures

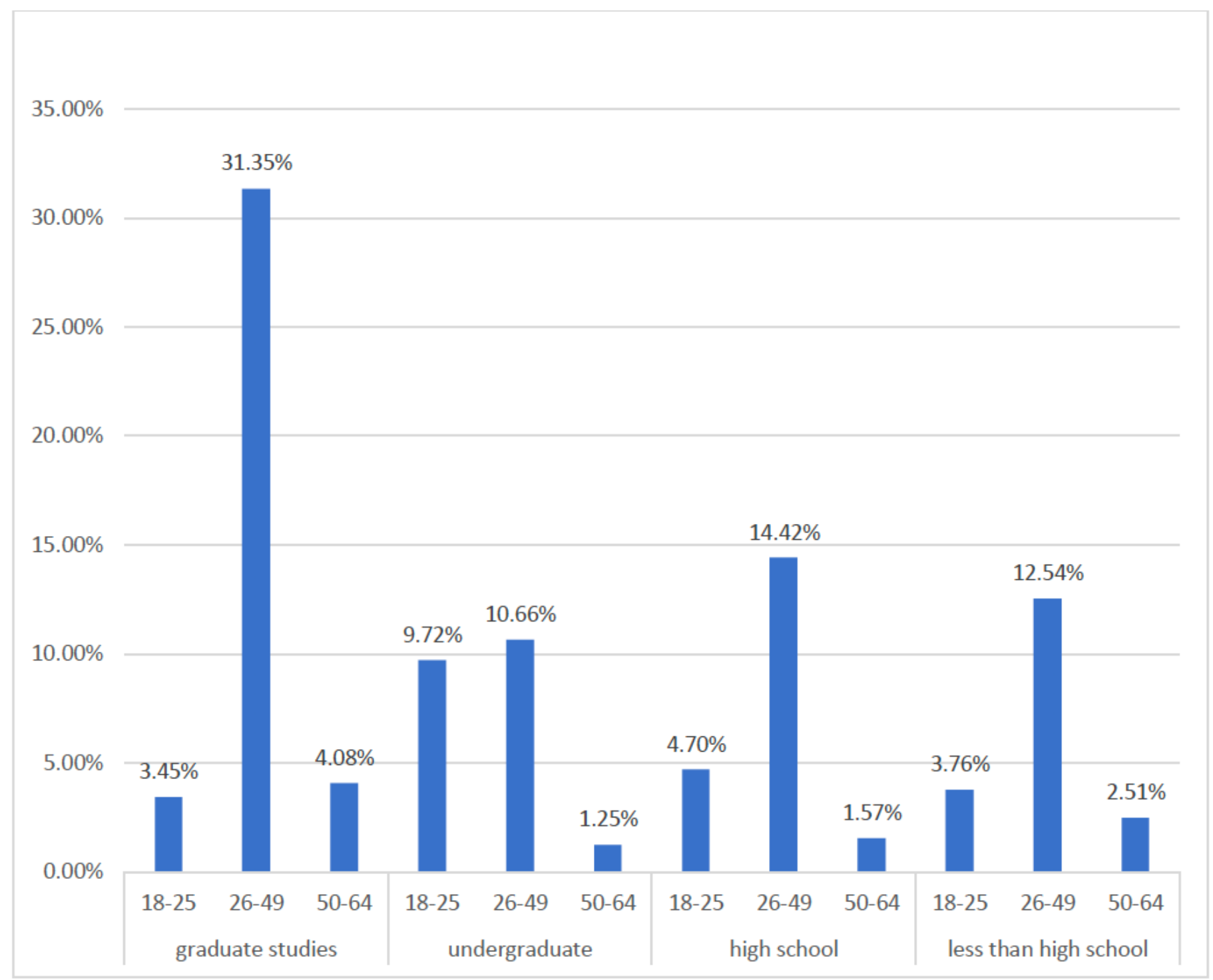

Education level distribution per age group; percentage of grand total for each category

Figure 1

Age group and Educational Level $(\mathrm{N}=319)$ 


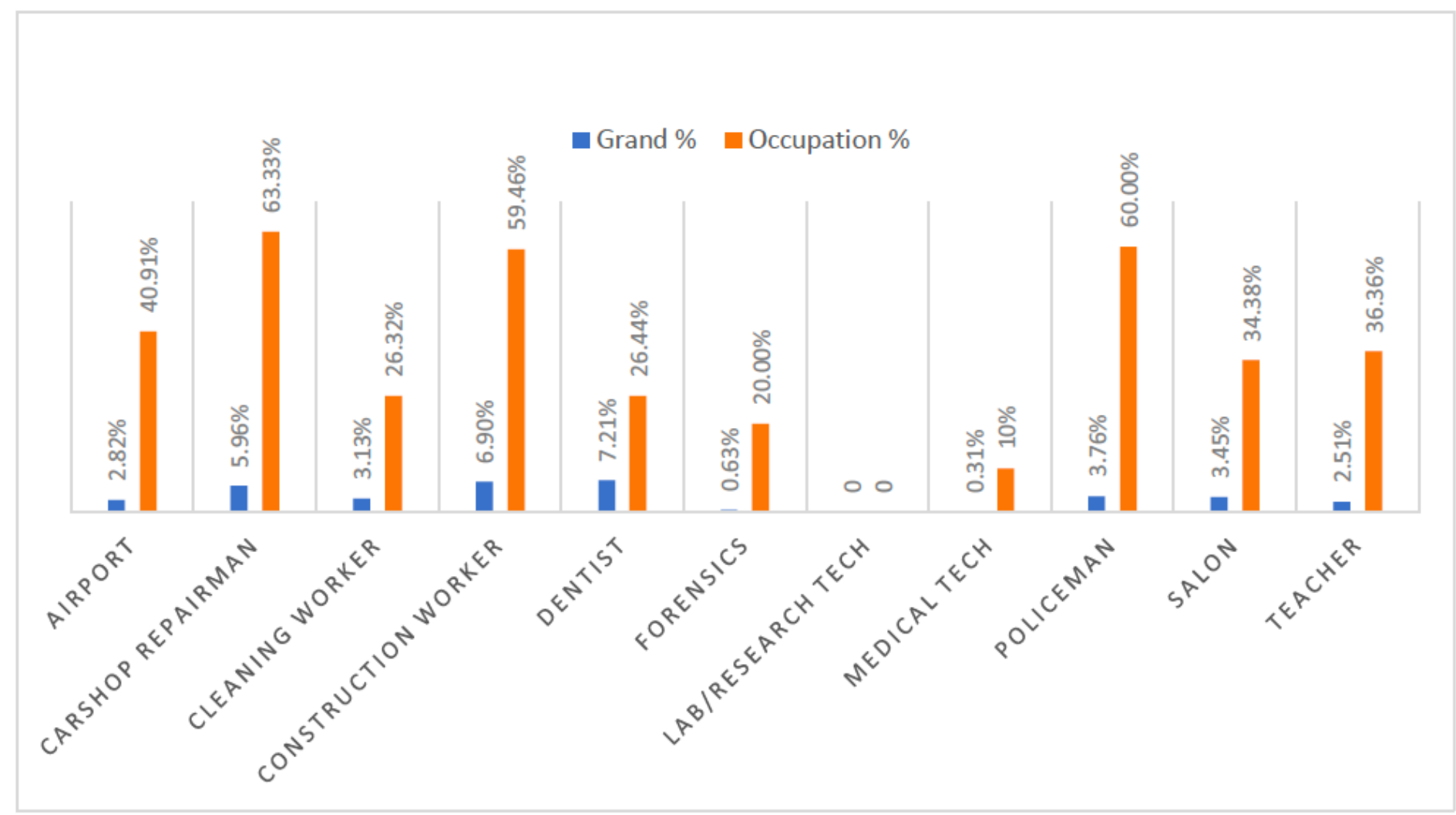

Smoking history; percentage of grand total (blue), percentage of occupation total (orange).

Figure 2

SMOKING HISTORY $(\mathrm{N}=319)$ 


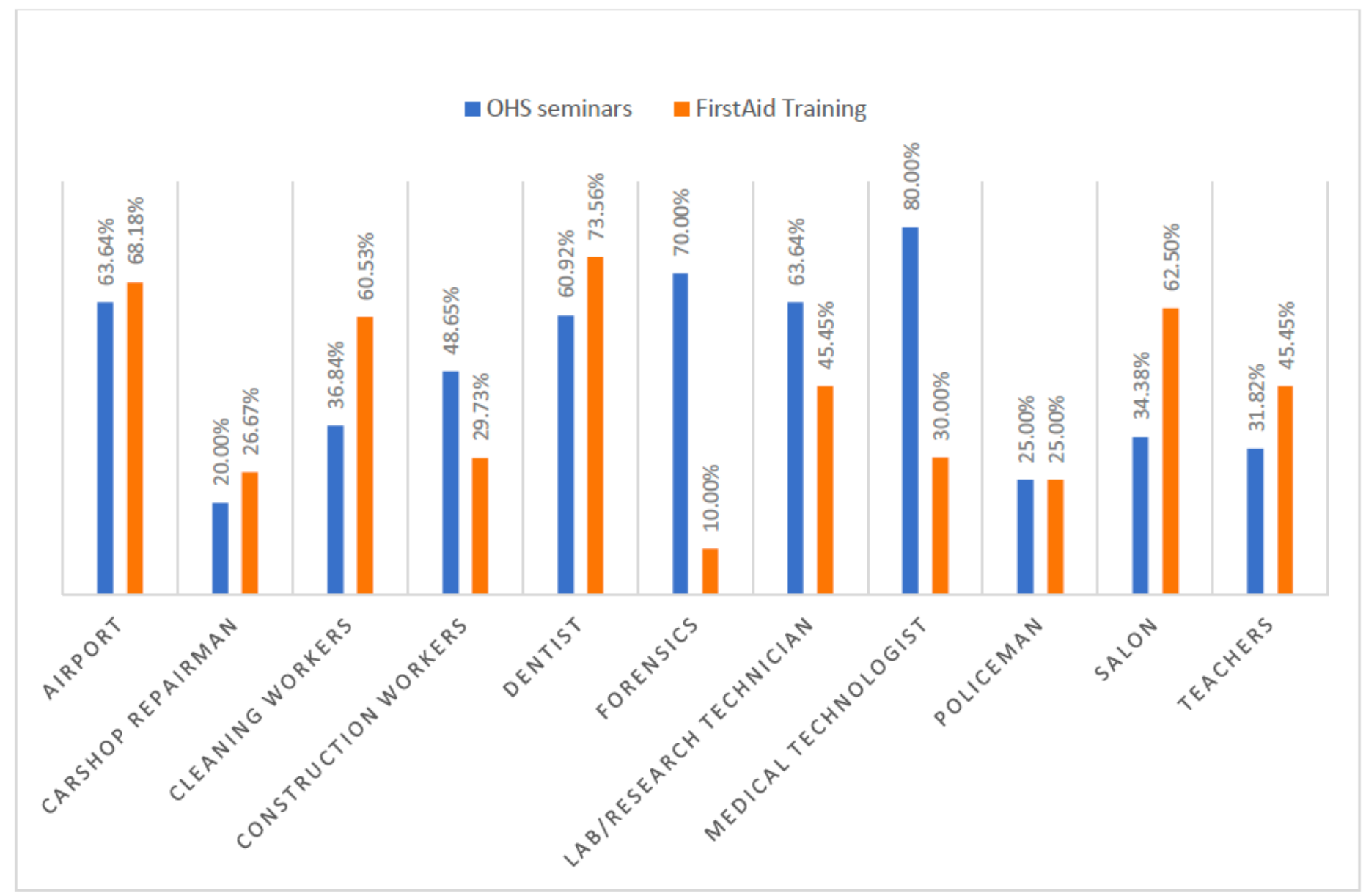

Safety training; percentage of occupation total for OHS seminars (blue) and First Aid training (red).

Figure 3

SAFETY TRAINING 


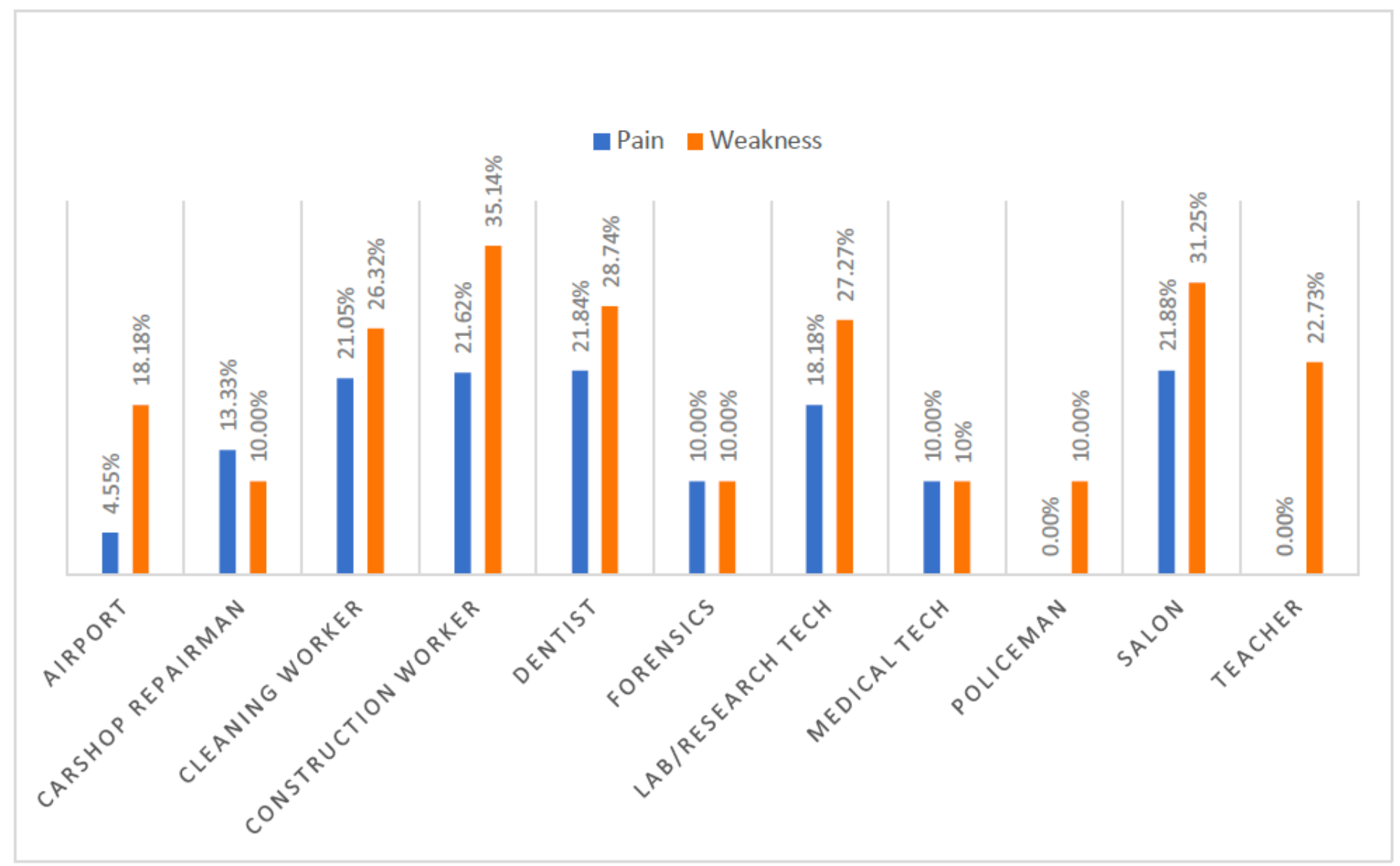

MSK occupation- related Symptoms; percentage of occupation total for Pain (blue) and Weakness (orange).

Figure 4

Musculoskeletal (MSK) Symptoms 


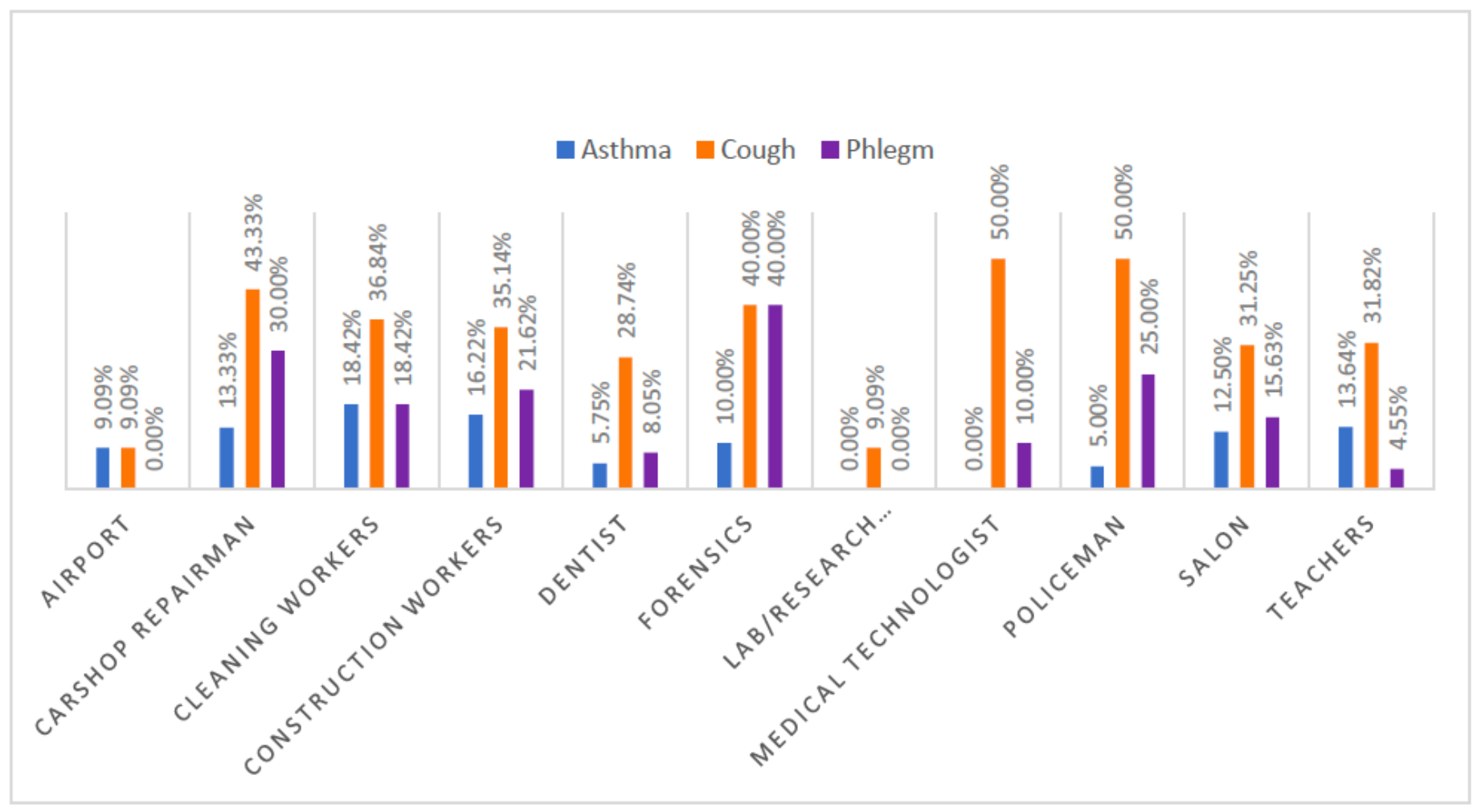

Respiratory occupational hazards; percentage of occupation total for Asthma (blue), Cough (orange) and Phlegm (purple).

Figure 5

RESPIRATORY SYMTOMS

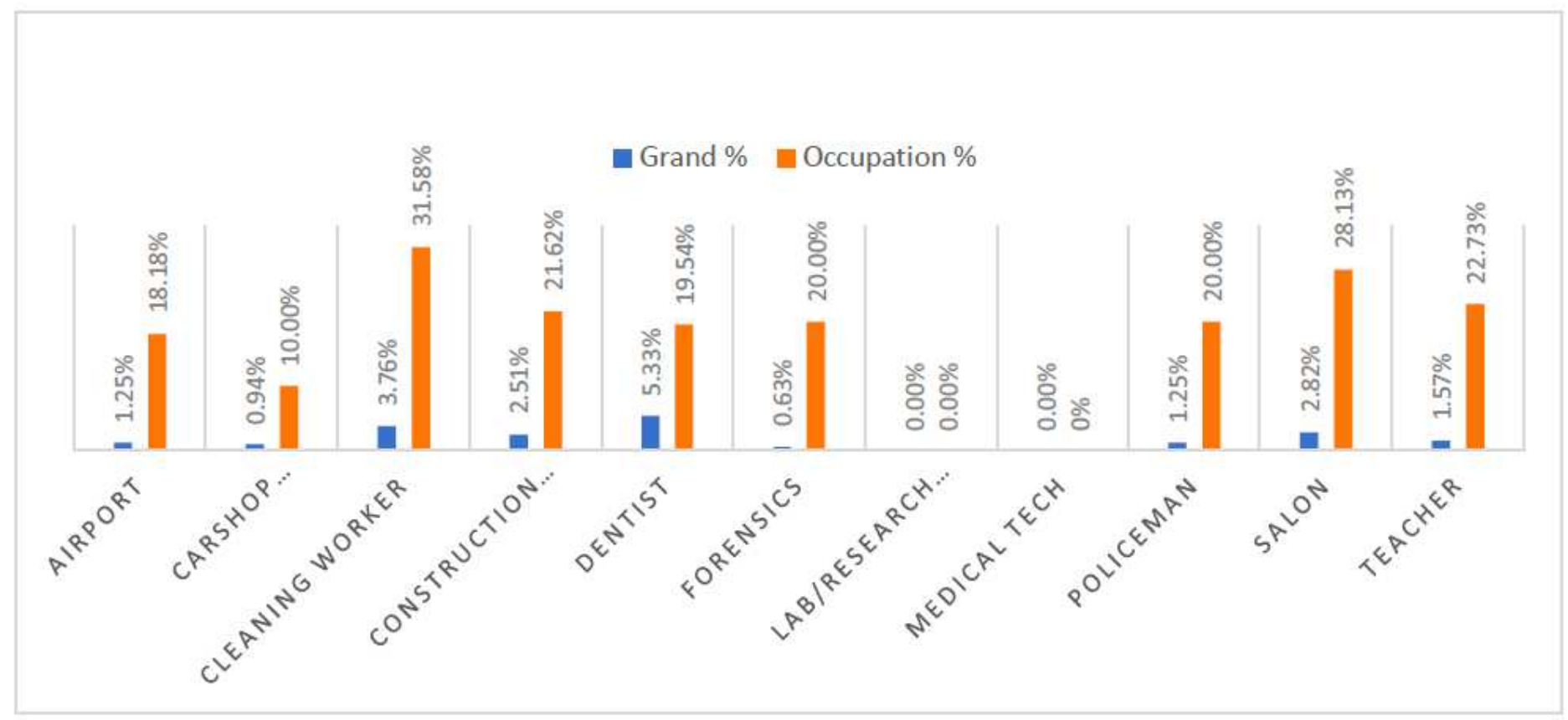

Stress and Anxiety; percentage of grand total (blue), percentage of occupation total (orange). 
Figure 6

PSYCHIATRIC SYMPTOMS

\section{Supplementary Files}

This is a list of supplementary files associated with this preprint. Click to download.

- EmployeesHealthAwarenessSurveyR.pdf

- EmployeesHealthAwarenessSurveyR.pdf 